\title{
PERBANDINGAN METODE INDEX CARD (TABLE) MATCH DAN TIMELINE DALAM PENINGKATAN HASIL BELAJAR MAHASISWA PADA PEMBELAJARAN SEJARAH KEBUDAYAAN ISLAM
}

\author{
Ahmad Zubaidi \\ Universitas Islam Indonesia, Yogyakarta, Indonesia \\ ahmad.zubaidi@uii.ac.id
}

DOI: 10.20885/tarbawi.vol12.iss2.art5

\begin{abstract}
The main problem in learning the history of Islamic culture is that it is boring and has too many historical perspectives. On the other hand, educators are expected to apply learning methods that are fun and make the students thinking critically. The purpose of this study is to look at the differences in the learning methods index card (table) match and timeline in improving student learning outcomes in the history of Islamic culture course. Afterwards, we will see the higher learning outcomes of the two methods. The research method used is experimental research with the sample of all 2020/2021 6th semester students, the department of Islamic Education, from Class $A$ and $C$ in the Islamic Cultural History course. Class $A$ is the control class with the index card (table) match method and class $C$ is the experimental class with the timeline method. The results of this study stated that there was difference between the two classes before and after the experiment, with $28.85 \%$ increase in the experimental class compared to $23.89 \%$ increase in the control class. This indicates that the experimental class has a higher level than the control class.
\end{abstract}

Keywords: Index Card (Table) Match Method; Timeline Method, History of Islamic Culture 


\title{
$e^{\text {I-Tarbawj Ahmad Zubaidi }}$
}

\begin{abstract}
Abstrak
Problematika utama pembelajaran sejarah kebudayaan Islam adalah pelajaran yang membosankan dan terlalu banyak perspektif sejarah. Di sisi lain, pendidik dituntut untuk menerapkan metode pembelajaran yang menyenangkan, tidak membosankan dan berfikir kritis. Tujuan penelitian ini melihat perbedaan metode pembelajaran index card (table) match dan timeline pada peningkatan hasil belajar mahasiswa matakuliah sejarah kebudayaan Islam. Selanjutnya, akan melihat hasil belajar yang lebih tinggi dari kedua metode tersebut. Metode penelitian yang digunakan adalah penelitian eksperimen dengan sampel seluruh mahasiswa semester 6 Kelas A dan C tahun ajaran 2020/2021 matakuliah Sejarah Kebudayaan Islam. Kelas A adalah kelas kontrol dengan metode index card (table) match dan kelas C adalah kelas eksperimen dengan metode timeline. Hasil penelitian ini menyatakan bahwa ada perbedaan diantara 2 (dua) kelas tersebut sebelum dan setelah dilakukan eksperimen, dengan masing-masing kelas eksperimen sebesar 28,45 nilai peningkatannya dibandingkan dengan kelas kontrol sebesar 23,89. Hal tersebut mengindikasikan bahwa kelas eksperimen lebih tinggi peningkatannya dibandingkan dengan kelas kontrol.
\end{abstract}

Kata Kunci: Metode Index Card (Table) Match, Metode Timeline, Sejarah Kebudayaan Islam

\section{PENDAHULUAN}

Masalah-masalah yang terjadi dalam pembelajaran sejarah kebudayaan Islam diantaranya adalah permasalahan metode pembelajaran yang masih menggunakan pola konvensional dengan ceramah (Widiani \& Jiyanto, 2019) yang membosankan mahasiswa saat pembelajaran (Umam \& Cahyadi, 2020). Begitu juga referensi yang sangat banyak yang membuat mahasiswa semakin bingung untuk mendapatkan kepastian dari waktu 
sejarah itu sendiri (Kazmi, 2005) serta persepsi siswa yang memandang sejarah sebagai pembelajaran yang membosankan (Hasmar, 2020). Di sisi lain, metode pembelajaran merupakan salah satu hal yang paling penting dalam proses pembelajaran itu sendiri. Metode pembelajaran yang tepat mempengaruhi banyak variabel termasuk motivasi peserta didik untuk dapat berpikir kritis (Lestari et al., 2018). Pemilihan metode pembelajaran yang tepat khususnya pada pembelajaran sejarah kebudayaan Islam juga menjadi salah satu factor penting yang harus dipersiapkan oleh guru untuk menunjang keberhasilan prestasi peserta didik (Parra, 2016). Begitu juga persiapan sebelum mengajar dalam menentukan metode yang tepat adalah salah satu kunci keberhasilan dalam pembelajaran salah satunya untuk menanggulangi kebosanan dalam pembelajaran (Shirani Bidabadi et al., 2016). Metode pembelajaran sejarah merupakan metode pembelajaran yang harus dipersiapkan secara lebih matang, jika sejarah itu sendiri merupakan pembelajaran yang terkesan membosankan dengan seringnya pengajar menggunakan metode konvensional berupa ceramah dan bercerita yang membuat peserta didik bosan dalam pembelajaran dan mengurangi hasil prestasi peserta didik itu sendiri.

Disamping itu pembelajaran Sejarah Kebudayaan Islam merupakan pembelajaran yang sangat penting untuk menanamkan modal rekonstruksi pendidikan yang ada di daerahnya khususnya di Indonesia (Arshad et al., 2012). Pembelajaran sejarah juga sangat penting kaitannya pada peserta didik terkait kesadaran politik dan budaya mereka (Alghamdi \& Achour, 2020). Persiapan yang matang sebelum 


\section{$e^{\text {I-Tarbawj Ahmad Zubaidi }}$}

dilaksanakannya pembelajaran SKI seperti menyusun RPP dan Silabus sangat mendukung keberhasilan pembelajaran (Hariyanto, 2019). Termasuk mempersiapkan metode pembelajaran dalam sejarah kebudayaan Islam merupakan hal yang harus dipersiapkan oleh pendidik agar pembelajaran yang berlangsung dapat berjalan dengan kondusif serta membuat peserta didik senang dengan apa yang sedang dipelajarinya yang notabene pembelajaran sejarah kebudayaan Islam tersebut lebih focus pada fenomena-fenomena zaman dulu atau kisah yang ada pada zaman tersebut.

Dalam upaya mengatasi pembelajaran sejarah dengan berbagai problematika tersebut khususnya dalam kejenuhan peserta didik dengan seringnya guru memakai metode ceramah, khususnya dimasa pandemic, maka alternatif metode yang menyenangkan sangat diperlukan untuk dipersiapkan oleh seorang pendidik sebelum melakukan pembelajaran salah satunya adalah metode index card (table) match sangat diperlukan untuk mengangkat motivasi siswa dalam melakukan pembelajaran. Menurut Zaini, metode pembelajaran ini sangat menyenangkan untuk digunakan dalam pembelajaran yang digunakan untuk mengulang materi yang telah diberikan sebelumhya. Materi barupun dapat diajarkan dengan catatan peserta didik diberi tugas mempelajari topik yang akan diajarkan terlebih dahulu sehingga ketika ia masuk di kelas sudah memiliki bekal pengetahuan (Zaini, 2008, p. 67). Aspek-aspek pembelajaran dengan metode ini diantaranya adalah sifat dan tujuannya berupa pengulangan materi sebelumnya, medianya berupa tabel, topik/konsepnya berupa satu pertanyaan dan jawaban, presentasi hasil belajarnya 
berupa kartu soal yang dibacakan didepan peserta didik, memiliki pasangan yang berperan mencocokkan dengan kartu jawabannya, penilaiannya berdasarkan kemampuan setiap pasangan, dan penutup pembelajarannya berupa klarifikasi dan kesimpulan (Maryati, 2010, p. 13). Kelebihan dari metode pembelajaran ini salah satunya adalah dapat menumbuhkan kegembiraan dalam proses pembelajaran, materi pembelajaran yang disampaikan dapat lebih menarik perhatian, dan mampu menciptakan suasana belajar yang aktif dan menyenangkan (Hamdani, 2011, p. 187).

Sedangkan dalam mengatasi problematika metode sejarah kebudayaan Islam dalam banyaknya referensi yang ada, maka alternatif metode timeline sangat tepat digunakan untuk meringkas berbagai referensi yang ada dan daya ingatan peserta didik. Metode ini kiranya tepat digunakan dalam pembelajaran daring berbasis asinkron, dikerjakan tanpa adanya pertemuan sinkron, serta tepat juga dalam membantu peserta didik mengingat, mengatur, dan mengekspresikan ideide yang kompleks dalam pembelajaran sejarah (Bremner, 2020). Secara tidak langsung, metode garis waktu (timeline) ini digunakan untuk lebih meningkatkan kreativitas peserta didik dalam belajar sejarah kebudayaan Islam dalam menghadapi berbagai referensi yang ada (DeCoito, 2020). Dalam pembelajaran sejarah, perbandingan waktu yang ada sangat dibutuhkan dan menjadi bahan penting untuk dianaliasis, dan metode garis waktu ini adalah pola pilihan metode yang menawarkan cara inovatif untuk mepresentasikan dan membandingkan kronologi pembelajaran sejarah kebudyaan Islam (Tasker, 2018). Metode timeline adalah garis waktu, 


\section{$e^{\text {I-Tarbawj Ahmad Zubaidi }}$}

merupakan representasi dari kronologis urutan peristiwa atau jadwal aktivitas dan dibuat menurut abad, tahun, era, bulan, minggu, hari, dan jam (Sadiman, 2008, p. 37). Termasuk dalam pemilihan metode sejarah yang menarik adalah dapat membangkitkan minat tentang materi dan teknik yang digunakan oleh para sejarawan agar siswa dapat memahami bagaimana penulisan sejarah itu sendiri, metode ini baiknya dapat memberi peserta didik untuk masuk ke ruang kerja para sejarawan supaya peserta didik mengetahui macam-macam interpretasi kejadian-kejadian sejarah serta karakter-karakter yang saling bertentangan (Kochar, 2010, p. 258). Adapun langkah-langkah pembelajarannya adalah menyampaikan tujuan pembelajaran, apersepsi tetang pentingnya sejarah kebudayaan Islam, membuat timeline semenarik mungkin, penjelasan peristiwa, tanya jawab, membuat kesimpulan, dan menarik sebuah rekonstruksi dengan membuat timeline oleh peserta didik (Sukandari, 2018).

Dari permasalahan dan diskusi teori yang ada di atas, maka penulis memberikan sebuah kontribusi pada tulisan ini dengan hasil perbandingan dari pembelajaran sejarah kebudayaan Islam pada tingkat mahasiswa yang mana 1 (satu) kelas dilakukan dengan metode pembelajaran index card (table) match dan kelas lainnya dilakukan dengan metode pembelajaran timeline (garis waktu) yang mana menurut penulis keduanya adalah metode yang tepat untuk mengurangi problematika pembelajaran sejarah kebudayaan Islam yang ada saat ini dan kiranya pembaca dapat memilih salah satu metode yang tepat dengan melihat hasil dari penelitian ini, atau dimungkinkan untuk melakukan blended learning 
(mencampurkan keduanya). Adapun tujuan dari penelitian ini adalah untuk melihat ada tidaknya perbedaan yang terjadi pada metode pembelajaran index card (table) match dan timeline pada peningkatan hasil belajar mahasiswa mata kuliah sejarah kebudayaan Islam mahasiswa serta jika ada perbedaan manakah hasil belajar yang lebih tinggi dari penerapan kedua metode tersebut, serta hipotesis yang ada adalah $\mathrm{H}_{a}=$ ada perbedaan antara 2 (dua) metode pembelajaran tersebut, $\mathrm{H}_{0}=$ tidak adanya perbedaan antara 2 (dua) metode pembelajaran

\section{METODE PENELITIAN}

Penelitian ini menggunakan jenis penelitian eksperimen murni yang mana desain penelitian ini menggunakan rancangan dengan memberikan tes pada awal pembelajaran dan akhir pembelajaran dengan kelompok kontrol (the randomized pretest - posttest control group design) dapat digambarkan sebagai berikut:

$$
\begin{array}{llll}
\mathrm{R}_{1}=\mathrm{O}_{1} & \mathrm{X}_{1} & \mathrm{O}_{2} \\
\mathrm{R}_{2}=\mathrm{O}_{3} & \mathrm{X}_{2} & \mathrm{O}_{4}
\end{array}
$$

Populasi dalam penelitian ini adalah seluruh mahasiswa semester 6 (enam) Program Studi Pendidikan Agama Islam Jurusan Studi Islam Fakultas Ilmu Agama Islam Universitas Islam Indonesia pada tahun ajaran 2020/2021 pada mata kuliah Sejarah Kebudayaan Islam. Adapun pengambilan sampelnya dilakukan dengan cara cluster random sampling (sampel diambil secara acak) yakni dengan membuat kocokan kemudian yang 


\section{$e^{\text {I-Tarbawj Ahmad Zubaidi }}$}

keluar adalah kelas A dan kelas C dari 4 kelas A, B, C, dan D semester 6 (enam) yang berjumlah 165 diambil kelas $A$ dengan jumlah 37 orang dan kelas $\mathrm{C}$ berjumlah 42 orang. Kelas A merupakan kelas kontrol dengan metode index card (table) match dan kelas C merupakan kelas eksperimen dengan metode timeline.

Analisis deskriptif statistik digunakan dalam penelitian untuk melihat deskripsi data penelitian dari hasil belajar mahasiswa yang meliputi mean, median, modus, nilai terendahtertinggi, rata-rata, dan standar deviasi di kelas eksperimen dan kontrol pada saat sebelum dilakukan pembelajaran. Setelah itu kemudian dilakukan uji normalitas, homogenitas, dan kemudian dilakukan uji kesamaan dua rata-rata yang digunakan untuk melihat ada perbedaan atau tidaknya dari 2 kelompok sampel dengan menggunakan SPSS pengujian independent sample t-test dengan kriteria pada equal varians assumed untuk data homogen dan equal varians not assumed untuk data tidak homogen, H0 diterima jika Sig.(2-tailed) nilainya lebih besar dari 0.05. Teknik pengumpulan data pada penelitian ini menggunakan tes dan angket. Tes digunakan dalam melihat hasil belajar mahasiswa, dan angket digunakan untuk mengetahui motivasi belajar siswa.

Adapun teknik analisis data dalam penelitian ini yakni hasil belajar mahasiswa setelah dilakukan perlakuan dengan menggunakan statistik deskriptif sama seperti diatas. Adapun uji hipotesis penelitian ini ada dua yakni, uji Independent Sample T-Test dengan taraf signifikansi 5\% yang digunakan untuk mengetahui ada tidaknya perbedaan antara 2 (dua) kelompok eksperimen dan uji Paired Sample T-test dengan taraf 
Perbandingan Metode Index Card (Table) Match Dan Timeline...

signifikansi 5\% yang digunakan untuk mengetahui rata-rata hasil belajar mahasiswa dengan metode index card (table) match lebih tinggi atau lebih rendah atau sama dengan rata-rata hasil belajar mahasiswa dengan metode timeline.

\section{HASIL}

\section{Pre-test}

Sebelum dilakukan perlakuan yang dilakukan dalam kelas eksperimen sebanyak 37 mahasiswa didapatkan data deskriptif statistik yakni mahasiswa rata-rata nilai mahasiswa akan aspek sejarah yang ada sebesar 52,20 yang mana nilai terendahnya adalah 42 dan nilai tertingginya adalah 67 serta didapatkan standar deviasinya adalah 5,265. Adapun untuk kelas kontrol sebanyak 42 mahasiswa didapatkan rata-rata nilainya adalah 55,98 dengan nilai terendahnya adalah 35 dan nilai tertingginya adalah 67,8 serta standar deviasinya sebesar 9,567 .

Kemudian sebagai syarat analisis statistic didapatkan nilai signifikansi dari kedua kelas tersebut dengan pembagian kelas kontrol memiliki nilai signifikansi 0,198 dan kelas eksperimen memiliki nilai signifikansi sebesar 0,078 yang mana kedua nilai tersebut lebih dari 0,05 yang bermakna bahwa data dari penelitian ini berdistribusi normal. Selanjutnya, dilakukan uji Levene Statistik yang mana uji akan menentukan bahwa proses datanya akan memakai uji equal variances assemed atau not assemed. Dari uji levene diketahui bahwa nilai signifikansi yang dihasilkan dari kedua kelas (kelas kontrol dan eksperimen) 


\section{$e^{\text {I-Tarbawj Ahmad Zubaidi }}$}

berdasarkan hasil nilai belajar uji pre-test yang dilakukan adalah 0,143 yang mana nilai tersebut lebih dari 0,05 yang berarti bahwa du akelas tersebut memiliki posisi yang sama atau homogen yang selanjutnya untuk uj kesamaan rata-ratanya nanti menggunakan uji equal variances assemed.

Selanjutnya, peneliti mengetahui perbedaan dari hasil nilai sebelum dilakukan perlakuan dengan menggunakan uji independent sampel t-test dengan melihat nilai signifkansinya. Dari data yang didapatkan, dihasilkan bahwa nilai signifikansi (2-tailed) equal variances assumed dari dua kelas (kontrol dan eksperimen) sebesar 0,179 yang mana nilai tersebut lebih besar dari 0,05 yang berarti bahwa Ha diterima. Kesimpulannya, tidak ada perbedaan antara dua kelas (kontrol dan eksperimen) sebelum dilakukan perlakuan (pre-test) dan kedua kelas tersebut memiliki kemampuan yang sama.

\section{Post-test}

Setelah dilakukan perlakuan yang dilakukan dalam kelas eksperimen sebanyak 37 mahasiswa didapatkan data deskriptif statistik yakni mahasiswa rata-rata nilai mahasiswa akan aspek sejarah yang ada sebesar 80,65 yang mana nilai terendahnya adalah 65 dan nilai tertingginya adalah 97 serta didapatkan standar deviasinya adalah 9,987. Adapun untuk kelas kontrol sebanyak 42 mahasiswa didapatkan rata-rata nilainya adalah 79,87 dengan nilai terendahnya adalah 64 dan nilai tertingginya adalah 91,5 serta standar deviasinya sebesar 8,987.

Kemudian sebagai syarat analisis statistic didapatkan nilai signifikansi dari kedua kelas tersebut dengan pembagian kelas 
kontrol memiliki nilai signifikansi 0,228 dan kelas eksperimen memiliki nilai signifikansi sebesar 0,178 yang mana kedua nilai tersebut lebih dari 0,05 yang bermakna bahwa data dari penelitian ini berdistribusi normal. Selanjutnya, dilakukan uji Levene Statistik yang mana uji akan menentukan bahwa proses datanya akan memakai uji equal variances assemed atau not assemed. Dari uji levene diketahui bahwa nilai signifikansi yang dihasilkan dari kedua kelas (kelas kontrol dan eksperimen) setelah dilakukan perlakuan berdasarkan hasil nilai belajar uji post-test yang dilakukan adalah 0,201 yang mana nilai tersebut lebih dari 0,05 yang berarti bahwa dua kelas tersebut memiliki posisi yang sama atau homogen yang selanjutnya untuk uj kesamaan rata-ratanya nanti menggunakan uji equal variances assemed.

Selanjutnya, peneliti mengetahui perbedaan dari hasil nilai setelah dilakukan perlakuan dengan menggunakan uji independent sampel t-test dengan melihat nilai signifkansinya. Dari data yang didapatkan, dihasilkan bahwa nilai signifikansi (2-tailed) equal variances assumed dari dua kelas (kontrol dan eksperimen) setelah dilakukan perlakuan sebesar 0,002 yang mana nilai tersebut lebih kecil dari 0,05 yang berarti bahwa H0 diterima. Kesimpulannya, didalam 2 kelas tersebut setelah dilakukan perlakuan terdapat perbedaan rata-ratanya, serta $\mathrm{t}$ hitung menunjukkan nilai positif yang bermakna bahwa rataratanya kelas eksperimen lebih tinggi dibanding dengan kelas kontrol. 


\section{$e^{\text {I-Tarbawj Ahmad Zubaidi }}$}

\section{Analisis Perbandingan}

Untuk mengetahui perbedaan diantara kedua kelas tersebut (kelas kontrol dan eksperimen) maka perlu dilakukan uji Paired Sample Test. Dari uji yang dilakukan oleh peneliti pada kelas eksperimen dihasilkan nilai signifikansi sebesar 0,001 yang mana nilai tersebut berarti bahwa hipotesis utama (H0) diterima yakni ada perbedaan yang signifikan antara kelas sebelum diberi perlakuan dan setelah diberikan perlakuan dari nilai rata-ratanya (pre-test dan post-test). Dalam tabel yang ada di uji $\mathrm{T}$ (tabel $\mathrm{t}$ ) pada kelas eksperimen diperoleh hasil negative yang mana nilai rata-rata sebelum perlakuan lebih rendah daripada nilai rata-rata setelah perlakuan. Hal ini juga dapat dilihat dalam nilai rata-rata sebelum perlakuan adalah 52,20 dan setelah perlakuan didapatkan nilai rata-rata sebesar 80,65. Maknanya, bahwa disana ada 28,45 peningkatan hasil belajar mahasiswa. Adapun Dari uji yang dilakukan oleh peneliti pada kelas kontrol dihasilkan nilai signifikansi sebesar 0,000 yang mana nilai tersebut berarti bahwa hipotesis utama (H0) diterima yakni ada perbedaan yang signifikan antara sebelum diberi perlakuan dan setelah diberi perlakuan dari nilai rataratanya (pre-test dan post-test). Dalam tabel yang ada di uji $\mathrm{T}$ (tabel t) pada kelas eksperimen diperoleh hasil negative yang mana nilai rata-rata sebelum perlakuan lebih rendah daripada nilai rata-rata setelah perlakuan. Hal ini juga dapat dilihat dalam nilai rata-rata sebelum perlakuan adalah 55,98 dan setelah perlakuan didapatkan nilai rata-rata sebesar 79,87 . Maknanya, bahwa disana ada 23,89 peningkatan hasil belajar mahasiswa 


\section{PEMBAHASAN}

Dari data yang didapatkan oleh penulis di atas dapat ditarik sebuah pembahasan yakni terdapat perbedaan antara kelas kontrol dan eksperimen yang pelaksanaan/perlakuannya menggunakan metode timeline dalam peningkatan hasil belajar mahasiswa pada mata kuliah sejarah kebudayaan Islam Program Studi Pendidikan Agama Islam Jurusan Studi Islam Fakultas Ilmu Agama Islam Universitas Islam Indonesia semester 6 (enam) tahun ajaran 2020/2021. Dalam kelas eksperimen yang menggunakan perlakuan dengan metode timeline hasilnya lebih tinggi dibandingkan kelas kontrol yang perlakuannya menggunakan metode index tabel match.

Hal tersebut dimungkinkan karena dalam kelas eksperimen yang perlakuannya menggunakan metode timeline ada sebuah kompetisi antara kelompok yang satu dengan kelompok yang lainnya, didalamnya pendidik tidak hanya memberikan materi dasar untuk dilakukan permainan dengan menggunakan garis waktu, tetapi mahasiswa juga diajak untuk masuk dan terjun kedalamnya seakan-akan mereka juga ikut menikmati dari proses sejarah yang sedang dipresentasikan. Dalam penggunaan metode garis waktu (timeline) juga memungkinkan peserta didik untuk meningkatkan motivasinya dalam menggali referensi sejarah yang ada dalam mengembangkan konteks sejarah yang sedang dipelajari, meningkatkan visualisasi peserta didik serta membuat pembelajaran semakin interaktif (DeCoito, 2020). Dalam pelaksanaannya menggunakan metode timeline ini mahasiswa dituntut untuk berfikir kritis atas kejadian-kejadian yang ada 


\section{$e^{\text {I-Tarbawj Ahmad Zubaidi }}$}

dalam sejarah, yang mana hal tersebut memungkinkan mahasiswa untuk mencari referensi sebanyak-banyak atas telaah kejadian sejarah yang ada pada garis waktu tertentu, hal tersebut didukung dengan sebuah penelitian yang menyatakan memang garis waktu menuntut mahasiswa untuk berfikir kritis (Kolar et al., 2015). Dalam pelaksanaan pembelajarannya oleh dosen pengampu, mahasiswa juga dituntut untuk merekonstruksi dengan menganalisis peristiwa demi peristiwa yang terjadi dalam garis waktu, yang mana kegiatan tersebut tidak dilakukan dalam kelas kontrol yang menggunakan metode index card (table) match. Hal tersebut sesuai dengan penelitian yang dilakukan oleh Brian bahwa metode garis waktu dapat memberikan kesempatan peserta didik untuk merekonstruksi pengalaman peristiwa sejarah untuk masa depannya (de Vries et al., 2017).

Dalam hasil yang telah dipaparkan oleh peneliti, bahwa kelas eksperimen telah menghasilkan 28,45 nilai peningkatan rata-rata yang didapatkan dari nilai pembelajaran dengan menggunakan metode timeline. Tidak menutup kemungkinan bahwa peningkatan rata-rata yang lain dipengaruhi oleh variabel yang lain juga termasuk dengan penggunaan metode index card (table) match dikarenakan kelas kontrol dengan pengujian pre-test dan post-test juga mengalami penaikan ratarata hasil belajar siswa sebesar 23,89 yang tidak berbanding jauh dari kenaikan rata-rata hasil belajar kelas eksperimen dengan menggunakan metode timeline. Hal tersebut dikarenakan model kompetisi juga dilakukan secara lebih ketat dalam pembelajaran yang ada di kelas kontrol dengan menggunakan metode index card (table) match yang 
memungkinkan untuk meningkatkan motivasi peserta didik dalam melakukan pembelajaran. Hal tersebut dilakukan penelitian sebelumnya oleh Khusnaini yang menyatakan bahwa memang dalam pembelajaran yang menggunakan metode index card (table) match dapat menarik perhatian peserta didik (peningkatan motivasi belajar) tetapi hasil belajar yang didapatkan belum maksimal (Fauzi, 2017). Dimungkinkan karena salah satu langkah-langkah pembelajarannya ada sedikit perbedaan dari teori aslinya, yang murni menggunakan kartu untuk menerapkan metode tersebut, tetapi dalam penelitian ini kartu yang digunakan dirubah menjadi tabel yang disamakan dengan penggunaan kartu yang ada dikarenakan pembelajaran yang tidak memungkinkan saat pandemic covid-19. Sebenarnya, pembelajaran dengan menggunakan metode ini pendidik juga menerapkan pembelajaran dalam tahapan HOTS (Higher Order Thinking Skills) yang mana penelitian sebelumnya juga menyebutkan bahwa pembelajaran dengan menggunakan metode ini dapat meningkatkan pemikiran kritis peserta didik (Bayasut, 2019).

Jika dilihat dari hasil yang telah didapatkan dari 2 (dua) kelas kontrol dan eksperimen terdapat selisih 4,56 nilai ratarata hasil belajar mahasiswa pada pembelajaran sejarah kebudayaan Islam. Selisih tersebut bukan termasuk selisih yang sangat besar dalam perbandingan hasil pembelajaran yang menggunakan metode timeline dengan index card (table) match. Keduanya memiliki peningkatan jika dilihat dari hasil pre-test dan post-test yang telah dilakukan oleh pendidik, tetapi hanya saja kelas eksperimen yang menggunakan metode timeline memiliki kenaikan yang lebih besar dibandingkan dengan kelas 


\section{$e^{\text {I-Tarbawj Ahmad Zubaidi }}$}

kontrol yang menggunakan perlakuan dengan metode index card (table) match. Hal tersebut jika dilihat dari hasil belajar mahasiswa terdapat perbedaan yang mencolok pada aspek penguasaan materi yang dihasilkan oleh mahasiswa dari aspek penilaian yang berupa keaktifan, penguasaan materi, berfikir kritis, dan ketepatan waktu yang digunakan dalam mengenalisi peristiwa sejarah. Faktanya dalam pembelajaran yang telah dilakukan, metode index card (table) match lebih focus pada kompetisi yang dilakukan oleh mahasiswa yang mana penguasaan materi yang digunakan kurang memberikan kontribusi yang kuat untuk memberikan hasil belajar mahasiswa yang maksimal, mereka lebih termotivasi dan banyak peran dalam melakukan kompetisi bermain kartu tabel yang sudah dirancang dan disusun oleh pendidik sedangkan materi yang disampaikan/dikembangkan oleh mahasiswa hanya stagnan pada materi yang telah disampaikan oleh pendidik. Berbeda dengan pembelajaran yang dilakukan dengan menggunakan metode timeline yang mana mahasiswa dituntut untuk mengisi bagian dari garis waktu yang masih kosong dan hal itu merupakan pengembangan materi yang telah disampaikan oleh dosen. Mereka harus mampu menganalisis peristiwa-peristiwa yang terjadi pada garis waktu tersebut selain peristiwa yang sudah disampaikan oleh pendidik (dosen) dan memungkinkan sekali bagi mereka untuk melakukan pengembangan materi (dari referensi yang berbeda) dengan mengisikan garis waktu yang masih kosong selain perisitiwa yang memang sudah ada dalam garis waktu tersebut (materi yang telah disampaikan oleh dosen). 
Maka dari itu, sangat memungkinkan sekali untuk pengembangan metode pembelajaran selanjutnya yakni dengan menggunakan metode pembelajaran blended learning antara metode pembelajaran index card (table) match dengan metode timeline dalam pembelajaran sejarah kebudayaan Islam pada jenjang mahasiswa. Hal tersebut memungkinkan untuk terjadinya sebuah penaikan rata-rata hasil belajar siswa yang sangat signifikan dibandingkan dengan hasil penelitian ini. Upaya dalam menutup kesenjangan dalam selisih nilai rata-rata hasil belajar mahasiswa kemungkinan dapat diatasi dengan penerapan dari kedua metode tersebut dengan mempertimbangkan pertemuan silang dalam pembelajaran sejarah kebudayaan Islam jenjang mahasiswa.

\section{KESIMPULAN}

Dari hasil penelitian yang telah dilakukan dapat disimpulkan bahwa terdapat perbedaan pembelajaran dengan menggunakan metode index card (table) match dengan pembelajaran yang menggunakan metode timeline pada mata kuliah sejarah kebudayaan Islam jenjang mahasiswa di Program Studi Pendidikan Agama Islam Jurusan Studi Islam Fakultas Ilmu Agama Islam Universitas Islam Indonesia tahun ajaran 2020/2021. Didapatkan nilai rata-rata kelas eksperimen (menggunakan metode timeline) lebih tinggi dibandingkan dengan kelas kontrol (menggunakan metode index card (table) match). Adapun nilai rata-rata dari kelas eksperimen didapatkan hasil 28,45 nilai peningkatannya dibandingkan dengan kelas kontrol sebesar 23,89 sedangkan hal yang mempengaruhinya adalah metode index card (table) match 


\section{$e^{\text {I-Tarbawj Ahmad Zubaidi }}$}

kurang fokus pada penguasaan dan pengembangan materi sejarah kebudayaan Islam dikarenakan peserta didik lebih mementingkan kompetisi (permainan) yang ada di dalamnya.

Saran dari peneliti untuk pengembangan selanjutnya, mencoba untuk melakukan metode blended learning antara kedua dari metode yang ada dalam penelitian ini, hal tersebut diharapkan dapat meningkatkan kembali nilai rata-rata hasil belajar peserta didik pada mata kuliah sejarah kebudayaan Islam.

\section{DAFTAR PUSTAKA}

Alghamdi, H., \& Achour, M. (2020). The Importance of Studying History on individual's awareness: A Case Study of Muslim Students in Saudi Arabia. Indonesian Journal of Islamic History and Culture, 1(2), 80-89. https://doi.org/10.22373/ijihc.v1i2.599

Arshad, I. S. M. R., Rozali, E. A., \& Kamaruzzaman, A. F. (2012). The Importance of Learning Islamic History and Civilization of Malaysia in the Building of Human Capital and Identity of the Muslim Society in Malaysia. Procedia Social and Behavioral Sciences, 59. https://cyberleninka.org/article/n/1024829

Bayasut, F. H. (2019). The Effect of Index Card Match Method to The Math Critically Thinking Skill Oriented to Higher Order Thinking Skills (HOTS). Indonesian Journal of Mathematics Education, 2(2), 81-88. https://doi.org/10.31002/ijome.v2i2.1746

Bremner, N. (2020). Time for Timelines: The Take-Home Timeline as a Tool for Exploring Complex Life Histories. International Journal of Qualitative Methods, 19, 
1609406920948978.

https://doi.org/10.1177/1609406920948978

de Vries, B., LeBlanc, A. J., Frost, D. M., Alston-Stepnitz, E., Stephenson, R., \& Woodyatt, C. (2017). The Relationship Timeline: A Method for the Study of Shared Lived Experiences in Relational Contexts. Advances in Life Course Research, 32 , 55-64.

https://doi.org/10.1016/j.alcr.2016.07.002

DeCoito, I. (2020). The Case for Digital Timelines in Teaching and Teacher Education. International Journal of E-Learning $\mathcal{E}$ Distance Education / Revue Internationale Du e-Learning et La Formation à Distance, 35(1), Article 1. http://www.ijede.ca/index.php/jde/article/view/1171

Fauzi, K. (2017). Cooperative Learning Index Card Match Model To Improve The Result of Qur'an Hadith Learning. MUDARRISA: Jurnal Kajian Pendidikan Islam, 9(1), 53-73. https://doi.org/10.18326/mdr.v9i1.53-73

Hamdani, H. (2011). Strategi Belajar Mengajar. Rineka Cipta.

Hariyanto, H. (2019). The Implementation Of Learning Islamic Cultural History (SKI) at MTs Al Washliyah 16 Perbaungan. International Conference on Islamic Educational Management (ICIEM), 1(1), Article 1. http://jurnal.uinsu.ac.id/index.php/iciem/article/view/7363

Hasmar, A. H. (2020). Problematika Pembelajaran Sejarah Kebudayaan Islam Di Madrasah. Jurnal MUDARRISUNA: Media Kajian Pendidikan Agama Islam, 10(1), 15-33. https://doi.org/10.22373/jm.v10i1.6789

Kazmi, Y. (2005). The Rise and Fall of Culture of Learning in Early Islam. Islamic Studies, 44(1), 15-51. 


\section{$e^{\text {I-Tarbawj Ahmad Zubaidi }}$}

Kochar, S. K. (2010). Pembelajaran Sejarah Teaching of History. PT. Gramedia Widiasarana Indonesia.

Kolar, K., Ahmad, F., Chan, L., \& Erickson, P. G. (2015). Timeline Mapping in Qualitative Interviews: A Study of Resilience with Marginalized Groups. International Journal of Qualitative Methods, 14(3), 13-32. https://doi.org/10.1177/160940691501400302

Lestari, A., Maridi, M., \& Ashadi, A. (2018). The Importance of Appropriate Instructional Methods for Training Students' Thinking Skill on Environmental Learning. International Journal of Pedagogy and Teacher Education, 2(0), 5-45-52. https://doi.org/10.20961/ijpte.v2i0.19828

Maryati, M. (2010). Meningkatkan Prestasi Belajar IPS Melalui Model Pembelajaran Indeks Card Match Pada Siswa Kelas IV SDN Tangkil Kulon Kec Kedungwuni Kab. Pekalongan [Skripsi]. PGSD FKIP Universitas Muhammdiyah Purwokerto.

Parra, B. J. (2016). Learning Strategies And Styles as a Basis For Building Personal Learning Environments. International Journal of Educational Technology in Higher Education, 13(1), 4. https://doi.org/10.1186/s41239-016-0008-z

Sadiman, S. (2008). Media Pendidikan. PT. Raja Grafindo Persada.

Shirani Bidabadi, N., Nasr Isfahani, A., Rouhollahi, A., \& Khalili, R. (2016). Effective Teaching Methods in Higher Education: Requirements and Barriers. Journal of Advances in Medical Education \& Professionalism, 4(4), 170-178.

Sukandari, K. (2018). Peningkatan Pemahaman Konsep Melalui Metode Timeline. Pedagogik: Jurnal Pendidikan Guru Sekolah dasar, 6(1). 
Perbandingan Metode Index Card (Table) Match Dan Timeline...

Tasker, I. (2018). Timeline Analysis Of Complex Language Learning Trajectories: Data Visualisation As Conceptual Tool And Method. Applied Linguistics Review, 9(2-3), 449473. https://doi.org/10.1515/applirev-2017-0001

Umam, M. S., \& Cahyadi, R. A. H. (2020). The Problematics of Learning The History of Islamic Culture in The 2013 Curriculum in Madrasah Aliyah Isy Karima Karanganyar Solo. Studia Religia : Jurnal Pemikiran Dan Pendidikan Islam, 4(2), Article 2. http://dx.doi.org/10.30651/sr.v4i2.6774

Widiani, D., \& Jiyanto, J. (2019). Improving Student Learning Outcomes In Lessons Of History Of Islamic Civilization Through The Application Of Bingo Strategies. J-PAI: Jurnal Pendidikan Agama Islam, 6(1), Article 1. https://doi.org/10.18860/jpai.v6i1.6716

Zaini, H. (2008). Strategi Pembelajaran Aktif. Pustaka Insan Madani. 